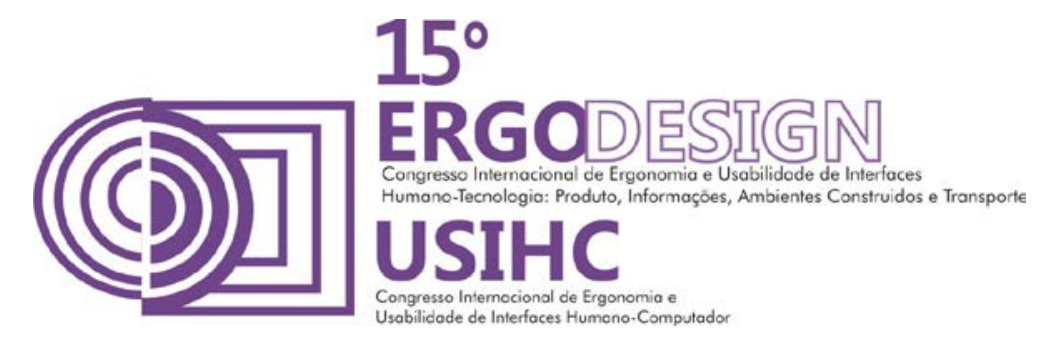

\title{
ESTUDO SOBRE O USO DE APLICATIVOS EM REALIDADE AUMENTADA PARA CONDUÇÃO DE VEÍCULOS COM ENFÂSE NA USABILIDADE
}

\author{
SOUZA, Andréa Silva (1); \\ TOSI, Sergio Rodrigues (2) \\ (1) $\mathrm{MS}^{\mathrm{a}}$ \\ e-mail: andreassouza@yahoo.com.br \\ (2) Universidade do Estado de São Paulo, DR \\ e-mail: srodrigu@fc.unesp.br
}

\begin{abstract}
RESUMO
Este artigo investiga, sob uma abordagem teórica, a usabilidade da interface dos softwares "ionroad" e "camonroad", em realidade aumentada (RA), aplicados na condução de veículos. Objetivando descobrir até que ponto a performance visual dos mesmos ajudando no trânsito focando apenas no funcionamento da interface. Para tal abordagem, tomar-se-á como base a percepção da usabilidade enfatizando eficiência, eficácia e satisfação.
\end{abstract}

\begin{abstract}
This paper investigates, from a theoretical approach, the usability of the software's interface "ionroad" and "camonroad" in augmented reality (AR), applied in conduction of vehicle. The main goal is to find out how the visual performance of the software helps in the traffic focusing on the operation of the interface work. To achieve this will be need a basic study on the perception of usability emphasizing efficiency, effectiveness and satisfaction.
\end{abstract}

\section{INTRODUÇÃO}

A realidade aumentada (RA), segundo Azuma, é a inserção de objetos virtuais no ambiente real. Os objetos podem sobrepor ou compor o ambiente, suplementando a realidade sem substitui-la parecendo que o virtual e o real coexistem no mesmo espaço. Funciona utilizandose de um marcador ("tag"), webcam e um computador, mas pode ser aplicada também em "tablets", "smartphones", "notebooks", dentre outras plataformas (AZUMA; 2001).

O marcador pode ser uma figura ou objeto, que esteja registrada no banco de dados do software em RA. De forma que, quando a webcam capta a imagem, da figura ou do objeto, automaticamente ativa, na tela, a simulação da RA correspondente. A RA pode ser multissensorial sendo manipulada por gestos, toques, sons, e é inter e multi disciplinar podendo estar presente em diversas áreas do conhecimento (MARTHA; 2013). 


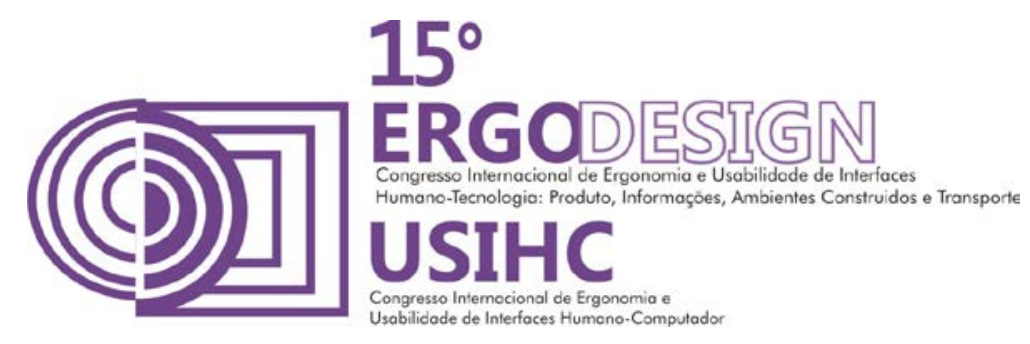

Para caracterizar a relevância da RA no momento atual, pode-se citar algumas pesquisas realizadas: o uso da RA tem sido fortalecido, pelo aumento crescente do número de celulares, como pode ser verificado pelo trabalho do núcleo de informações do ponto BR (Nic.BR), que atualizou em 2013 uma pesquisa sobre a quantidade de individuos que usaram telefone celular nos últimos meses. Nessa pesquisa, foi Identificado que $85 \%$ da população, a partir de 10 anos de idade, já usa celular, representando um crescimento de 18 pontos percentuais, no período de 2008-2013. No geral, temos hoje 3,2 milhões a mais de usuários em relação a 2012. Ainda com o intuito de mostrar a tendência crescente do mercado em torno da comunicação móvel, a mesma fonte publica um outro gráfico que mostra as atividades feitas no celular com e sem o uso da Internet. Onde $23 \%$ da população brasileira baixa aplicativos, um percentual que tende a crescer com a evolução e aperfeiçoamento dos mesmos. Esses dados são importantes por que refletem um simulacro de como trabalhar e lidar melhor com as tecnológias emergentes.

A aplicação automotiva também ganha mais espaço, e a industria tem todo interesse em desenvolver aplicativos para carro com RA, por exemplo, os seguintes softwares: "car finder", "camonroad", "AR GPS Drive Navigation" e "ionroad", encontram-se em fase de aperfeiçoamento.

A presente proposta de pesquisa pretende investigar o funcionamento da interface visual dos aplicativos em RA para condução de veículos e, dentro do contexto da plataforma móvel, descobrir se a performance dos mesmos podem tornar o condutor mais cauteloso. É também objetivo desse projeto, analisar o impacto de se adicionar informações em tempo real da situação do tráfico (acidentes, engarrafamentos, postos de gasolina, etc.), comparando o cumprimento das tarefas e verificando em quais condições a RA tem melhor desempenho.

Para poder averiguar tal influxo é preciso levar em conta aspectos, tais como: o conceito de atenção dividida, que é a habilidade de responder simultaneamente a multiplas tarefas ou demandas, sendo este considerado o ponto alto da atenção (WICKENS, C.D \& HOLLANDS, J.G; 2000) e; o espaço físico (mundo real) e as informações que se sobrepõem ao mesmo (RA) são importantes na hora de reduzir a cognição, pois a mudança do olhar entre as informações de RA e o espaço real (rua ou estrada) exige reflexos e eforços mais rápidos para agir enquanto se dirige.

É esperado que a sincronização e a coordenação da habilidade visual sejam potencializadas com o sistema da RA em termos de orientação sem distrações. Contando com a distância e velocidade com que os olhos se movimentam e o tempo em que este fica parado olhando em algum ponto específico, identificando assim, o grau da atenção.

O restante do trabalho é organizado nos seguintes tópicos: quinto tópico vai tratar da usabilidade móvel e as vantagens de usar a RA em aplicativos. Sexto tópico aborda a percepção digital dando um apanhado em torno do conceito, voltado a questão do processo de perceber e affordance.

No ultimo tópico será aparesentada a metodologia escolhida para desenvolver o trabalho e o metódo adotado para discutir os resultados finais. Depois vem a conclusão com as impressões e resultados finais. 


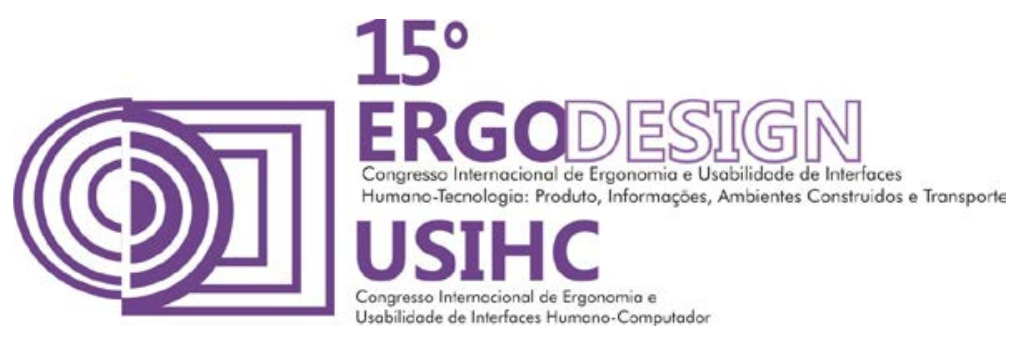

\section{FUNDAMENTAÇÃO TEORICA}

As aplicações da RA implementadas para ajudar na condução de veículos vem sendo introduzidas desde os trabalhos voltados para o metódo industrial (PANG Y.; NEE; A.YC; KAMAL; Youcef; ONG; S.K; YUAN; M.L; 2004), até o vislumbramento nas aplicações navegacionais. $\mathrm{O}$ condutor tem uma experiência mais imersiva e adequada para auxilia-lo nas tarefas e operação da direção do veículo, pois com o "Head Up Display" (HUD), a atenção fica ainda mais centrada nos eventos importantes, localização, objetos a frente, providenciando uma informação de visão espacial relevante (BARK; T; CUONG; FUJI; MURA;K.; HING, V.; 2013).

O HUD tem o propósito de oferecer, instrumentos de informação captados pelo painel, sobrepostos no campo de visão do condutor, eliminando a necessidade de olhar para baixo em outro painel. A RA, por outro lado, acrescenta na visão do usuário diferentes tipos de informações adicionais. Ambos sobrepõe gráficos no mundo real para engajar o entendimento do usuário (GRUPTA; 2004).

Kim e Dey descobriram que a mudança de foco do olhar do "display" GPS para a rua, somado ainda com o raciocionio extra de ter que processar as informações geradas, causa o problema da atenção dividida, pois esse esforço mental se soma com a não familiaridade do funcionamento do sistema causando barreiras para o condutor dirigir.

$\mathrm{Na}$ tentativa de resolver o problema da atenção visual, Markus, Frank e Gerhard comparam o "Head Up Display" (HUD) com o "Head Down Display" (HDD), utilizando-se do "eye tracking" para medir a frequência de distribuição das fixações do olhar. Para a informação do "display" ser captada o período, em que isso acontece, é definido pelo tempo de fixação mais o tempo de movimento do olhar. Resultados experimentais, com várias pessoas, mostram que 85\% dos participantes apontaram aceitação maior pelo HUD enquanto dirigia, sendo muito util em fornecer informações. No final, o HUD apresentou um grande potencial para desempenhar as tarefas de interação, no entanto, ainda há itens visuais a melhorar (MARKUS; TONY; FRANK; KALUS \& GERHARD; 2007).

Atualmente, uma grande quantidade de programas navegacionais de RA que mostram, na sua interface, o caminho realçado a ser seguido ou uma seta apontando diretamente para esse caminho, apresentam um problema relacionado ao fato de que, se um outro carro ou objeto passar pela frente da webcam, ocorre uma interferência causada pela sobreposição do objeto com o caminho a ser seguido, o sistema então não funciona mais como deveria e a consequência disso é um gráfico confuso para o condutor (BARK; T; CUONG; FUJI; MURA;K.; HING, V.; 2013).

Uma solução aplicada foi a introdução de um avatar, em RA, onde é menos provável haver interferências na visão do condutor. Uma contribuição, na direção de solucionar tal problema, foi proposta por Pionneer (2013), onde o mesmo desenvolveu um projeto chamado "cyber navi", no Japão, a ideia do projeto é mostrar as direções e informações, no campo de visão do condutor, em pequenas partes, reduzindo a poluição visual, desta forma a movimentação do olhar e a necessidade da mudança do foco de atenção são facilitadas. Neste trabalho, desenvolveu-se o primeiro HUD que faz a projeção no parabrisa do carro, em RA. Para tal, usou-se um laser que projeta as informações, sobre o tráfico, em alto contraste e alta definição. Dados como: distância do destino, progresso da rota, direção da viajem, distâncias dos outros 


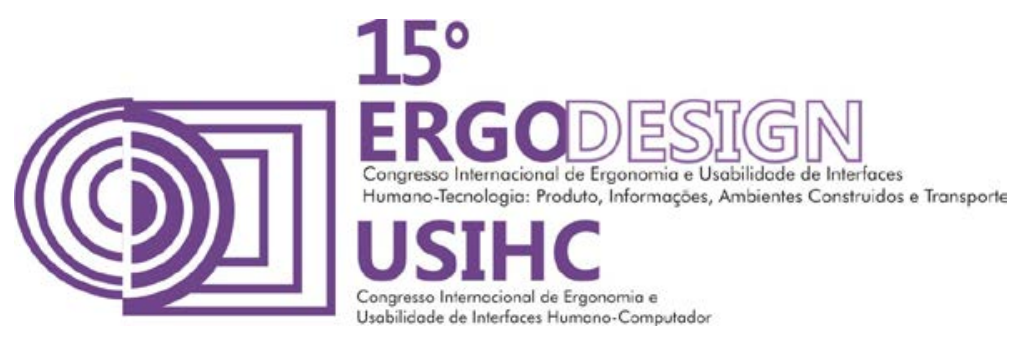

veículos a frente, recomendações de velocidades, melhores opções de caminho, dentre outras informações, são apresentadas no display.

Grupta identificou que neste cenário, quando as informações apareciam repetitivamente o resultado era gerar tensão nos olhos até que as pessoas se adaptassem a tela, a razão disso é que muito dos testes são feitos em simuladores sem dar a oportunidade de verificar a pronfundidade ideal dos gráficos visuais.

As consequências disso são que as mudanças provocadas pela distância dos alvos para o olho do usuário, causam fatiga visual, erro de estimação da distância dos objetos, estresse, por passar longos periodos de tempo nessas condições. Por exemplo, a máquina de "Touring" desenvolvida por Feiner (1997), foi o primeiro prótotipo movél em RA, e avaliou durante uma caminhada pelo campus universitário, o funcionamento da RA enquanto obtinha informações dos prédios e do ambiente.

Neste caso, foi usado um "display" (HUD), um computador para iteração e outros equipamentos. Os gráficos gerados apareceram muito confusos e foi difícil completar tarefas, tais como: andar e extrair informações em RA, ao mesmo tempo. Principalmente, na hora da mudança de foco do olhar em diferentes niveis de profundidade. Toda essa situação reforça a necessidade de um projeto centrado no usuário incorporando os fatores humanos na RA a fim de melhorar a percepção e cognição ao lidar com a interface da mesma.

$\mathrm{Na}$ tentativa de corrigir a questão da percepção em relação a profundidade do foco o instituto Honda desenvolveu, em 2013, um navegador chamado "personal navi" com HUD 3D que gera imagens utilizando focos de planos moveis de 5 metros para o infinito e 20 graus de campo de visão (KARLIN BARK, Cuong Tran, Kikuo Fujimura, Victor Ng-Thow-Hing).

A habilidade de projetar imagens em distâncias de focos precisas aos olhos do usuário permite um movimento mais apropriado e ainda registra as imagens virtuais sobre o mundo real reduzindo a fatiga visual. O objetivo era testar a qualidade do sistema verificando se dava para perceber antecipadamente aonde seguir e se ajudava a manter o olhar fixo na estrada.

Este estudo obteve sucesso, para a interface visual HUD 3D, mostrando ser significante em relação ao tempo de reconhecimento dos eventos e as imagens em RA não aparentaram influenciar no número de fixações do olhar, que se manteve mais fixo na estrada, em comparação ao HUD 2D. Porém, os testes foram somente indoor, faltando, em estudos futuros, analisar o problema em ambiente outdoor e verificar se os estímulos afetam a habilidade do condutor. Neste trabalho, faltou atestar com mais detalhes as questões relacionadas a latência dos imagens em RA e a sincronia entre os elementos visuais e o meio ambiente se movimentando, que podem causar problemas de percepção ao usuário (BARK; K., TRAN; C.; FUJIMURA; K.; NG-THOW-HING; V.; 2013).

Não foi investigado também o problema do caminho realçado (ou uso do avatar) que contraste melhor com a visão do usuário oferecendo usabilidade e melhor apreensão. Temos ausência também de considerar a mudança da quantidade de pixels por imagens durante 0 funcionamento da RA para não afetar a habilidade do usuário quanto a percepção. Houve também a falta de uma análise focada na interface visual do aplicativo com a finalidade de observar o que chama mais atenção, em termos dos elementos gráficos e "design", para contribuir como conteúdo relevante ao condutor. 


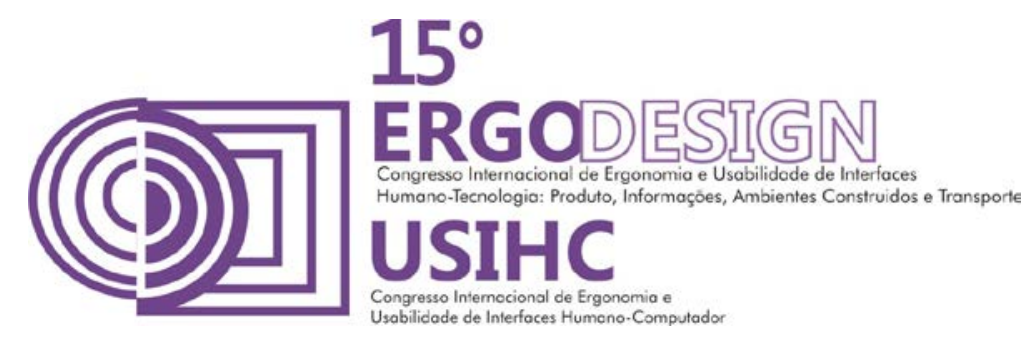

\section{HIPÓTESES}

Hipótese1: A RA pode melhorar a performance somente quando o condutor não conhece o caminho a seguir.

Hipótese2: A RA vai contribuir para melhorar a atenção visual do condutor no trânsito mostrando informações que o usuario sozinho não poderia diretamente detectar com seus próprios sentidos.

Hipótese3: A RA não atrapalha o desempenho das tarefas mesmo adicionando informações sobre o que está acontecendo no trânsito em tempo real.

Hipótese4: As imagens, textos e fundo na RA influenciam a performance positivamente, quando devidamente projetado.

\section{USABILIDADE MÓVEL}

A entrância da usabilidade, segundo Nielsen, é a facilidade de uso quanto mais prático e fácil de entender o produto melhor, pois a produção deve ser voltada ao usuário. Os objetivos precisam estar claros e devem ser alcançados com eficácia, eficiência e satisfação no contexto de uso.

Eficácia é a completude com que o usuário desempenha as suas tarefas sendo possível finaliza-las perfeitamente. Eficiência condiz com o nível de esforço que o usuário faz para concluir a tarefa, quanto menor, melhor. Satisfação que é a presença de atitudes positivas em relação ao produto. (QUARESMA; \& MORAES; 2011)

Quando a usabilidade é especificamente aplicada ao desenvolvimento de interfaces para dispositivos móveis é necessário atentar aos seguintes fatores:

a) Eliminar opções, para eliminar funções não fundamentais

b) Eliminar conteúdo, reduzindo a quantidade de palavras

c) Ampliar os elementos da interface

O ideal seria não limitar a seleção de produtos, pois a gama de itens deve permanecer a mesma. Otimiza-se o layout para as dimensões e orientação da tela, assim, os diferentes elementos são dispostos em uma grade flexível; a grade ajusta-se também as dimensões da tela.

Os tipos de aplicativos para celulares são: nativos, web e híbridos. Os aplicativos nativos referem-se aqueles projetados para a própria plataforma podendo ser instalados em uma loja de aplicativos como "Google play" ou "App Store". O aplicativo de web, é executado pelo navegador sendo instalados a partir de algum site e cria-se um ícone nos favoritos para acessar o site em que foi baixado. Em relação aos nativos, eles são mais limitados em recursos. Os aplicativos híbridos usam um navegador dentro do aplicativo, sendo instalados da mesma forma que os nativos, mas partes deles tem páginas web.

As quatro principais barreiras que os usuários enfrentam na usabilidade móvel são: telas muito pequenas, entrada desajeitada, especialmente para digitação, demora do "download", aplicativos mal projetados. Temos mais usabilidade se o aplicativo tiver comandos que podem 


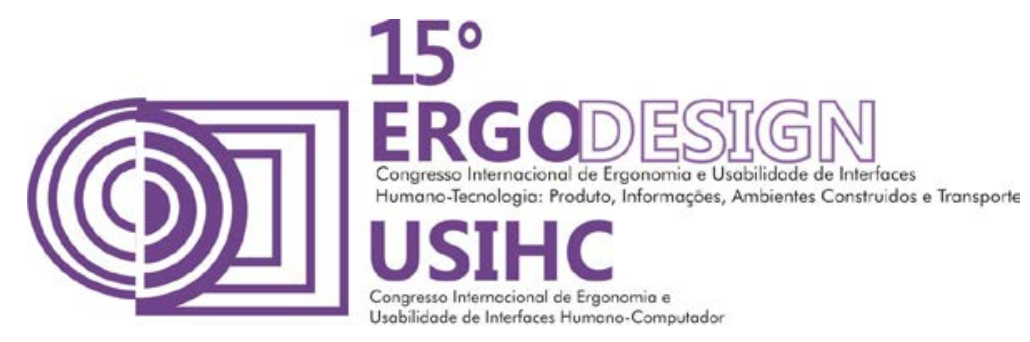

ser usados em contextos diferentes conseguindo igual resultado, e são eficientes por que possibilitam que os usuários aprendam uma coisa e a utilizem várias vezes reforçando a memória. (NIELSEN; 2014).

O pouco espaço na interface da tela pode ser organizado aumentando o tamanho das fontes e dividindo as informações em tópicos e sub tópicos, só tomando cuidado com o número de cliques que o usuário deve fazer no passo a passo das tarefas. No "download" o aplicativo deve avisar o tempo de demora para baixar o arquivo, assim como, a progressão do mesmo. Quanto ao processo de digitação, considerando que dentro dos aplicativos temos um texto que é uma síntese, o aplicativo ou apenas fornece uma breve legenda do assunto ou um "link" com a informação completa para que o usuário não precise perder tempo procurando o que quer.

O layout geral da interface consiste na Arquitetura de Informação (Al), definida pela questão de como estruturar os elementos (gráficos) ao longo na navegação possibilitando os usuários escolherem somente aquilo que Ihe interessa, entendendo e aproveitando o espaço disponível, inclusive, sabendo onde está, aonde vai e quais passos já deu. A Al voltada aos aplicativos móveis deve se adaptar ao contexto que tem o "design" do aplicativo, e para saber se vai ter sucesso (ou não) é preciso testar medindo o uso real e sustentável. Se o usuário usar uma vez ou poucas vezes, o projeto é falho, pois é essencial dar suporte as tarefas e modelos mentais do mesmo (NIELSEN; 2014).

Em suma, a usabilidade tem a ver com a qualidade da relação homem máquina e meio ambiente. No âmbito do design é necessário fomentar mais pesquisas investigando a nova forma de interação e performance da RA, observa-se também a falta de inclusão dispositivos móveis na análise da usabilidade, carecendo de um planejamento adaptativo para que o aplicativo seja responsivo e compreensível.

\section{PERCEPÇÃO DIGITAL}

A percepção não é só o que está acontecendo, mas também uma série de acontecimentos complexos adicionados ao entendimento da situação. Enquanto combinamos todas as ocorrências, eles fazem sentido no processo da organização do meio ambiente. Então, 0 processo de percepção ocorre quando nós somos treinados a perceber, identificar, sinais, sons, formas e outros (Goldstein, E. B. (1996)). O sistema determina o que está lá fora pegando informações para si, o processo de governar as interações dentre distintos componentes motor, é investigado sob a noção de coordenação.

O primeiro estudo de coordenação motor foi do russo fisiologista Nicholai Bernstein (1967) que definiu coordenação como "o processo de dominar graus redundantes de liberdade de movimento do organismo, em outras palavras, a conversão para o sistema de controle. Coordenação é a organização do aparato do controle motor" (BERNSTEIN, 1967, p. 127). Bernstein definiu habilidade como a capacidade de coordenar e controlar corretamente 0 movimento alcançando o objetivo da tarefa.

Toda essa explicação para o "design" da interface visual, é importante, pois precisamos ter a noção do funcionamento do olho e seus atributos para adapta-lo as condições de conforto do olhar fornecendo uma experiência intuitiva ao usuário. Dizendo respeito também ao "outflow" (o que é olhado a distância e altura) e "inflow" (o que vai passando). 


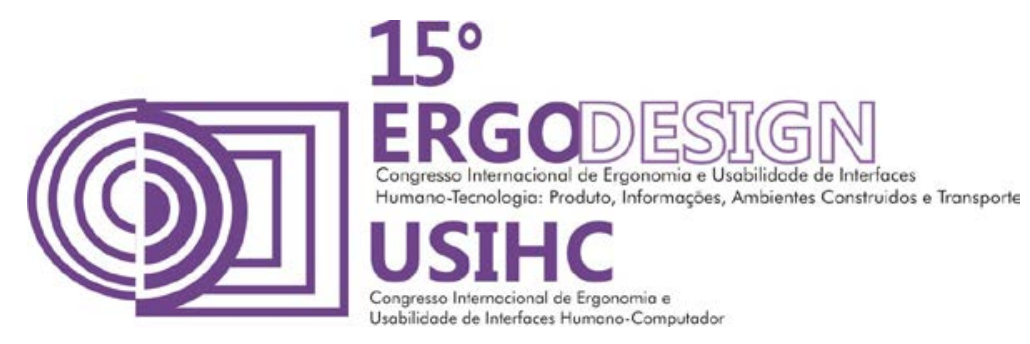

Ao perceber estamos vendo panoramas, atividades acontecendo, atribuindo aos eventos significados, assim, vem a questão do affordance que são as possibilidades das coisas no ambiente: o que me diz respeito, o que posso fazer, como estamos aptos aquilo, como se encaixa em relação ao que se percebe especificamente (GIBSON; 1979).

O ser humano tem um sistema complexo, toda informação compreendida para o funcionamento é voltada a redução de incertezas, assim, a informação obtida sofre transformação até a tomada de decisão efetivamente. Portanto, a memória vai extrair da experiência o que é importante comparando a referência dos resultados com o que já se tem internamente. Tudo isso envolve o processo de aprendizagem e aspectos perceptuais definindo ações e o que é necessário para ajustar habilidades. Quando entendemos a informação damos valor ao que foi construído internamente.

Refletindo sobre toda esta linha de pensamento, ao relacionar com o aspecto tecnológico, podemos direcionar ao aprendizado da técnica, pois quase tudo o que realizamos hoje em dia é técnica. Abranges tem uma frase muito interessante sobre a dominação da mesma: "busca saber o quão refém é um refém que já nasceu no domínio de seu sequestrador". Heidegger complementa afirmando que a técnica é a produção, ferramenta, máquinas pertencentes aos produtos, a técnica é o instrumento.

A RA é a máquina, o canal que traz disponibilidade de recursos para os nossos olhos enxergarem e apreenderem a técnica. A RA contribui para muitas vantagens em termos de percepção digital, devido simular em tempo real todas as partes, funções, características dos produtos, é capaz de antecipar futuros reparos ou evitar erros antes de produzir um protótipo, proporciona aos consumidores uma interação mais imersiva, dinâmica e realista, enquanto conhecem os produtos ou serviços (BRAGA; Martha 2013).

\section{METÓDOS}

Os principais métodos (procedimentos) que a pesquisa que pretende desenvolver é através de um experimento, gravando vídeos do funcionamento dos aplicativos em RA ("ionroad" e "camonroad") no trânsito comparando e depois, propor uma análise da interface, suas funções e limitações para obter uma opinião da utilização em termos de intuitividade, usabilidade, como os dados aparecem para o usuário.

\subsection{Etapas metodológicas}

O desenvolvimento das principais etapas do experimento desta pesquisa consiste em primeiramente avaliar a percepção do funcionamento dos aplicativos, enquanto a RA funciona em tempo real. Segundo, se caso puder, comprovar as hipóteses pelos resultados e o que poderia se aperfeiçoar em termos de interface visual.

\subsection{Experimentos}

O "Ionroad" é um aplicativo que usa RA para condução de veículos tendo como principais funções os alertas: "off road" (carro fora da pista), "warning" (perigo quando o carro se aproxima demais do outro), "carefull" (cuidado com algum outro carro se aproximando demais). Funciona 


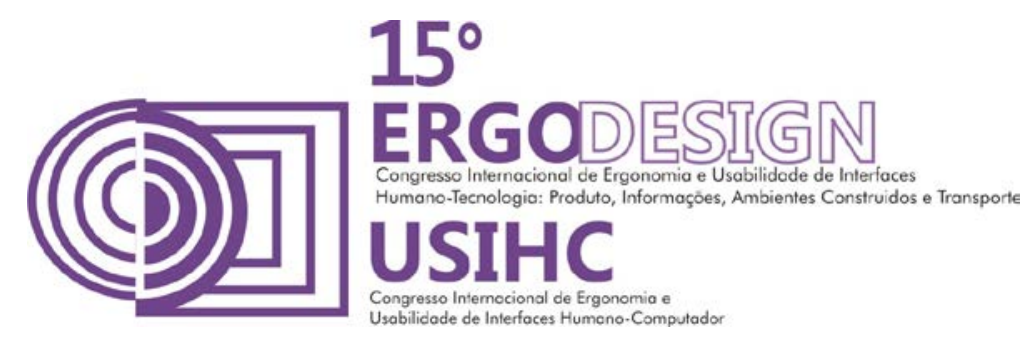

através da câmera do próprio celular que filma o que está acontecendo mostrando as informações em tempo real na RA.

No teste do vídeo, realizado na cidade de Bauru - São Paulo, com o aplicativo ("ionroad") foi filmado sua ação de mostrar as informações em RA, e funcionou perfeitamente durante o dia e noite, inclusive enquanto chovia e o para brisa permanecia ligado. Abaixo estão as figuras da sua interface:

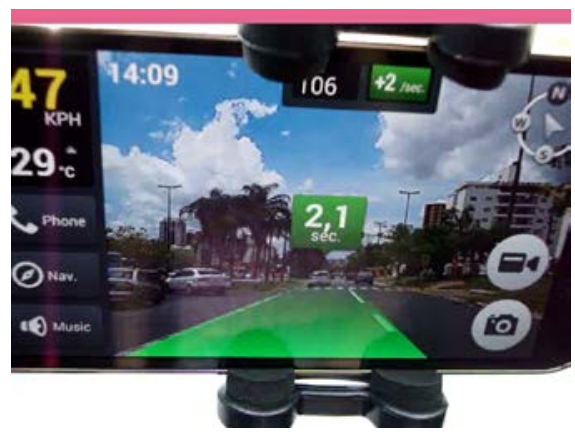

Figura 1

Fonte: IONROAD; 2015

$\mathrm{Na}$ interface deste aplicativo, podemos constatar, no menu esquerdo a velocidade em quilometros por hora que o carro percorre, a temperatura em graus celsius, é possível atender ligações na opções "phone" e abaixo temos a opção do navegador que traça a rota do destino.

O menu direito mostra uma bússola indicando o sentido que o carro segue, temos a figura de uma camera que é possível filmar a trajetória, mas a RA não aparece, somente o caminho normal. Depois, por último, uma figura de máquina, que o usuário pode tirar fotos do trajeto e compartilhar no facebook.

O caminho do asfalto é realçado com a cor verde durante todo o percursso e a velocidade que falta para chegar no carro a frente é mostrada no balão escrito "2,1 segundos", que muda de cor conforme os alertas, quando o mesmo está verde a distancia e velocidade são seguras.
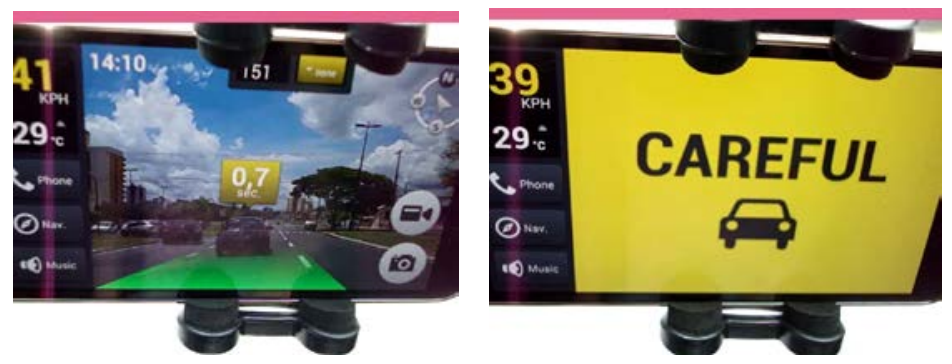

Figura 2 - Fonte: IONROAD; 2015 


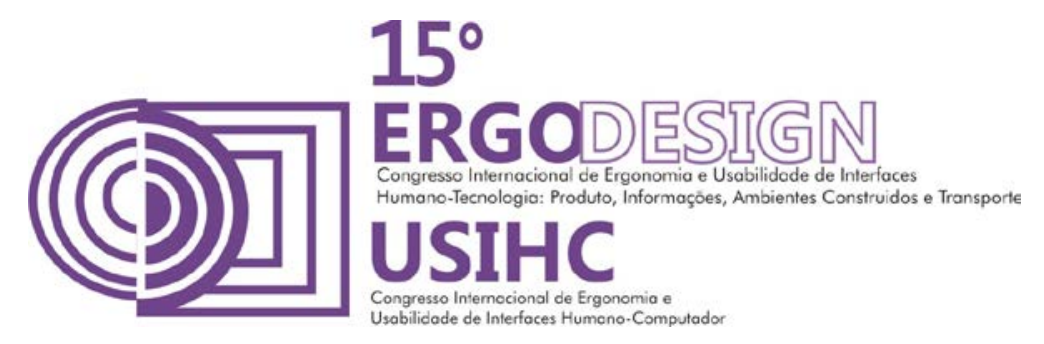

Quando o balão escrito "0,7 segundos", muda de cor para o amarelo a distancia e velocidade não estão muito seguras e um alerta é feito para o motorista na tela "CAREFUL", ou seja, "cuidado".
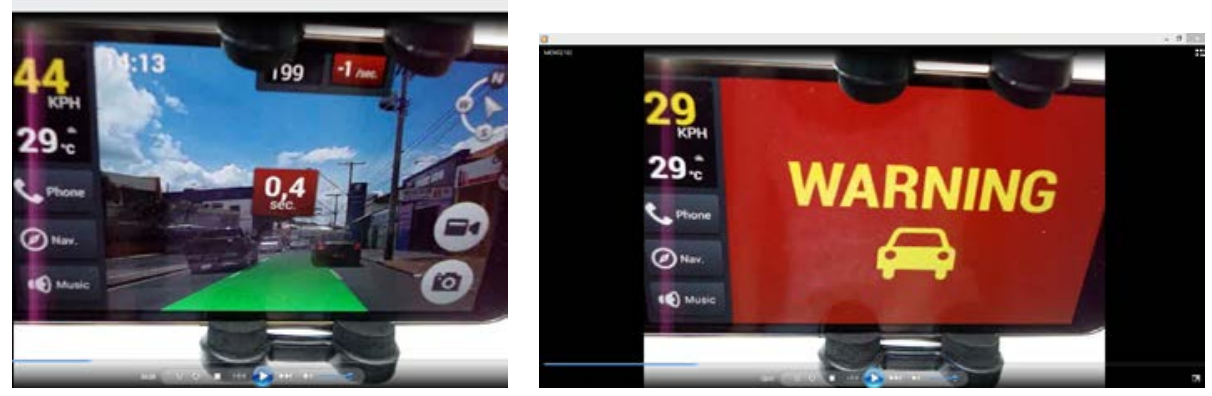

Figura 3

Fonte: IONROAD; 2015

Quando o balão escrito "0,4 segundos", muda de cor para o vermelho a distancia e velocidade não estão seguras e um alerta é feito para o motorista na tela "WARNING", ou seja, "perigo".

"Camonroad" foi o segundo aplicativo que usa RA para condução de veículos escolhido para o experimento, também seguindo o mesmo trajeto na cidade de Bauru - São Paulo. Suas principais funções são os comandos de voz do GPS indicando aonde seguir, dobrar, fazer retornos, recalcula rotas, no caso do condutor ter desviado o caminho.

No teste do vídeo usando o aplicativo foi filmado a ação de mostrar as suas informações em RA e funcionou perfeitamente durante o dia e noite, inclusive enquanto chovia e o para brisa permanecia ligado.
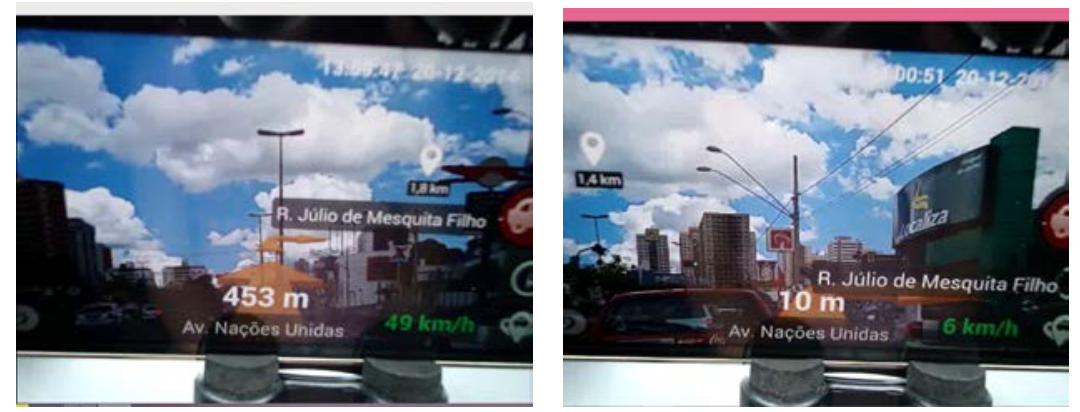

Figura 4

Fonte: IONROAD; 2015 


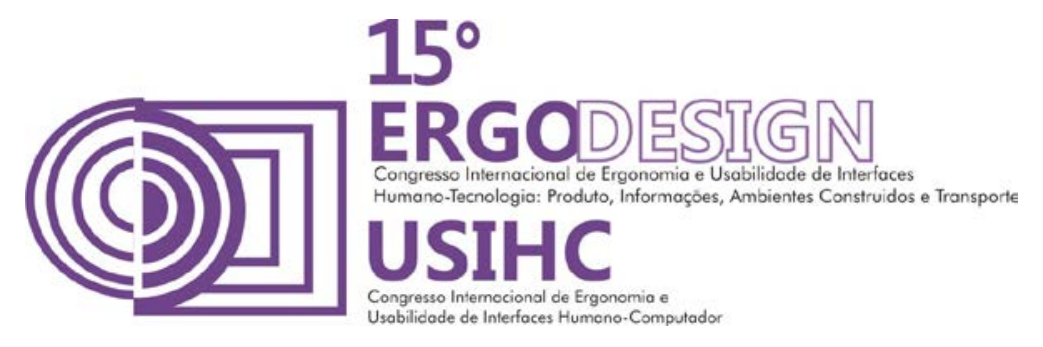

$\mathrm{Na}$ interface do aplicativo temos um menu a direita que permite configurar o destino que vai seguir, se o usuário que a voz do GPS, volume dos alertas, porém é preciso utilizar a Internet para que funcione.

Durante a rota do caminho o aplicativo realça o caminho através de uma seta laranja grande que mostra o percursso a seguir. Durante a trajetória temos um balão branco na tela escrito "1,4 km" que é quanto falta para chegar ao destino, assim como, o mesmo balão indica onde há postos de gasolina, lojas e shoppings.

O aplicativo também consegue informar quanto falta para dobrar em uma determinada rua, como no caso do exemplo dá figura, mostra "julio mesquita 453 metros" e "julio mesquita 10 metros" á medida que vai se aproximando. Já a velocidade em verde "49 km/h" e "6 km/h" é a velocidade que proprio carro está percorrendo.

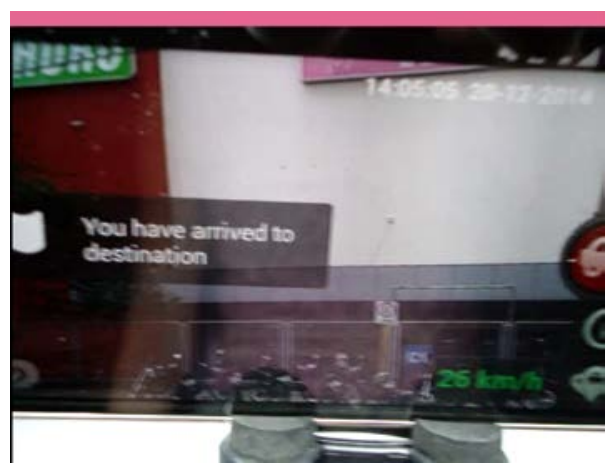

Figura 5

Fonte: IONROAD; 2015

O aplicativo também acusa quando o condutor chegou ao seu destino com um alerta e a bandeira branca aparece na tela.

Os dois aplicativos têm igual precisão no quesito do fornecimento de dados, a diferença na interface é que visualmente o "ionroad" realça o caminho com uma cor verde no asfalto e o "camonroad" utiliza uma seta grande laranja que destaca a direção aonde seguir.

No primeiro, falta a voz do GPS e as indicações poderiam ser melhores em quando seguir em frente, dobrar, retornos, que o segundo aplicativo apresenta. A interface, em ambos, é intuitiva e é fácil entender como manipular.

Constatou-se nos dois aplicativos a falta de usabilidade para não tornar os alertas uma distração para o motorista, não tinha opção de troca de idiomas, e a pergunta que fica seria se os mesmos só são uteis se o condutor não souber o caminho aonde ir. Devido nenhum dos dois aplicativos fornecerem informações que ensinem ao condutor a conduzir melhor o carro, ter melhores opções de caminhos, avisando sobre o trafego, por exemplo. Sinal de que o planejamento visual da interface precisa ser melhor projetado. 


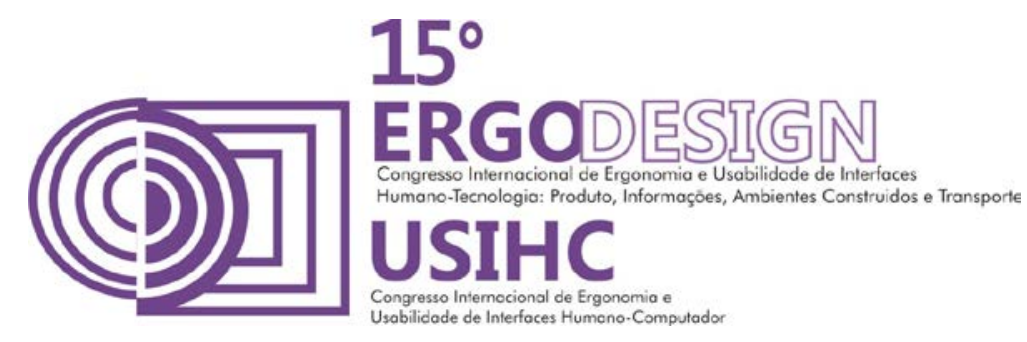

\section{CONCLUSÃO}

Este artigo estudou sobre o uso de aplicativos em RA na condução de veículos, focando no funcionamento da interface dos mesmos e, avaliando a usabilidade móvel, os resultados indicam que algumas das hipóteses apresentadas podem ser confirmadas como explicado a seguir:

A RA não atrapalha o desempenho das tarefas mesmo adicionando informações sobre o que está acontecendo no trânsito em tempo real. Esta hipótese foi confirmada, pois tanto o aplicativo "ionroad" como "camonroad" ajudaram lembrando da segurança na direção, porém, o segundo fornece instruções somente em inglês, então o condutor que não domina bem 0 idioma pode demorar um pouco até entender a instrução do aplicativo.

As imagens, textos e fundo na RA influenciam a performance positivamente, quando devidamente projetado. Esta hipótese foi confirmada, pois em termos de usabilidade é essencial tornar a interface acessível e fácil de entender, com ótima resolução e legibilidade.

A RA pode melhorar a performance somente quando o condutor não conhece o caminho a seguir. Está hipótese foi confirmada para o aplicativo "camonroad", que funciona igual a um GPS guiando o condutor aonde seguir.

Entretanto, no caso do "ionroad", apenas fornece instruções de alertas ao longo do caminho para que a atenção visual na condução seja reforçada, acredita-se que ele melhora a performance tanto quando o condutor sabe e não sabe o caminho a seguir.

A RA vai contribuir para melhorar a atenção visual do condutor no trânsito mostrando informações que o usuário sozinho não poderia diretamente detectar com seus próprios sentidos. Está hipótese é confirmada no caso do aplicativo "camonroad" além do GPS, ainda fornece informações sobre postos de gasolina, restaurantes, shoppings, etc ao longo do trajeto, caso o condutor precise.

Já o "ionroad" contribui também para atenção visual, mas de uma maneira diferente, o usuário é capaz de atentar as faixas, a distância que está do veículo a frente, se está indo para fora da pista etc. o que ele ajuda é apenas alertar sobre esses possíveis acontecimentos como forma de reforçar a performance positivamente.

\section{REFERÊNCIAS BIBLIOGRÁFICAS}

AZUMA; BAILLOT, Y., BEHRINGER, R., FEINER, S., JULIER, S., MACINTYRE, B. Recent Advances in Augmented Reality. Computers \& Graphics, November 2001

Bernstein, N. A. (1967). The coordination and regulation of movements. Oxford: Pergamon Press.

BRAGA; Marta C. Goulart Diretrizes para o design de mídias em realidade aumentada [tese]: situar a aprendizagem colaborativa online / Marta Cristina Goulart Braga; orientadora, Vânia Ribas Ulbricht. Florianópolis, SC, 2012.

FEINER, S., MacIntyre, B., Hollerer, T., \& Webster, A. (1997). A touring machine: Prototyping 3D mobile augmented reality systems for exploring the urban environment. IEEE Proceeding of the International Symposium on Wearable Computers, Cambridge, MA, 74-81.

GOLDSTEIN; Bruce E. Sensation and Perception UK, Pergamon Press; Vo. 03, pp. 191-195, 1981. 


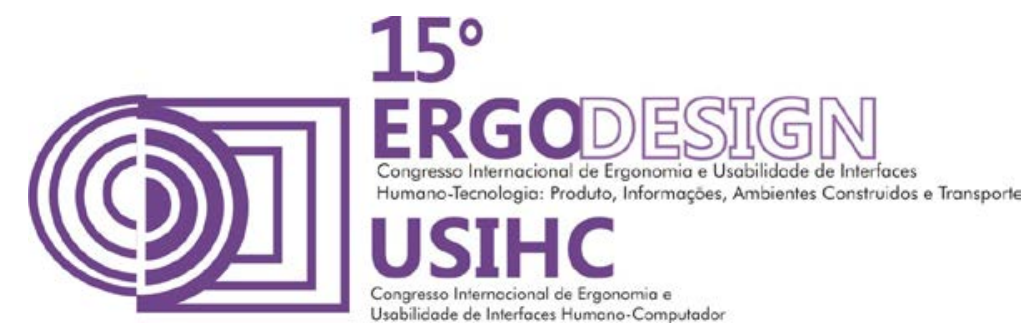

GRUPTA D; "An empirical study of the effects of context-switch, object distance, and focus depth on human performance in augmented reality." M.S. Thesis, 2004.

\section{HEIDEGGER, "técnica"}

KARLIN BARK, Cuong Tran, Kikuo Fujimura, Victor Ng-Thow-Hing Personal Navi: Benefits of an Augmented Reality Navigational Aid Using a See-Thru 3D Volumetric HUD Honda Research Institute USA 425 National Avenue, Mountain View, CA, 94043 USA; 2013.

Y.Pang, AY A.Y.C. Nee, Kamal Youcef-Toumi, S.K. Ong, M.L. Yuan,2004, "Assembly Design and Evaluation in a Augmented Reality Environment", National University of Singapore, Massachusetts Institute of Technology, pp.1-6.

PIONEER; "Cyber navi: Augmented reality head-up display." http://pioneer.jp/carrozzeria/cybernavi/avicvh0009hud avic-zh0009hud/.

MARKUS; TONY; FRANK; KALUS \& GERHARD; Eye gaze studies comparing head-up and headdown displays in vehicles Munich University Technology Institute for Human-Machine-Communication, Theresienstr, BMW Group Forschung \& Technik 2007

NICBR; 2014 Disponível em < http://cetic.br/publicacao/pesquisa-sobre-o-uso-das-tecnologias-deinformacao-e-comunicacao-tic-centros-publicos-de-acesso-2013> Acessado em dez 2014.

NILESEN; Jackob \& BUDIU Raluca Usabilidade Móvel Edição 1, Editora ST, 2013.

QUARESMA, M., Moraes, A. (2011). A Usabilidade de Tarefas Típicas de Seleção do Destino em Sistemas de Navegação GPS Automotivos. Prod., Volume 21, Número 2. In: http://www.scielo.br/scielo.php? Script=sci_arttext\&pid=S0103-65132011000200015\&lng=pt\&nrm=iso. Acessado em: 30.07.2014.

S. KIM and A. K. Dey, "Simulated augmented reality windshield display as a cognitive mapping aid for elder driver navigation," in Proc. of the SIGCHI Conference on Human Factors in Computing Systems, CHI '09, (New York, NY, USA), pp. 133-142, ACM, 2009.

WICKENS, C.D.; HOLLANDS, J. Engineering psychology and human performance. New Jersey: Prentice Hall, 2000 